\title{
Application of the Shiono and Knight Method in asymmetric compound channels with different side slopes of the internal wall
}

\author{
Wisam Alawadi ${ }^{1} \cdot$ Wisam S. Al-Rekabi² - Ali H. Al-Aboodi ${ }^{2}$ (i)
}

Received: 18 September 2017 / Accepted: 28 December 2017 / Published online: 22 January 2018

(c) The Author(s) 2018. This article is an open access publication

\begin{abstract}
The Shiono and Knight Method (SKM) is widely used to predict the lateral distribution of depth-averaged velocity and boundary shear stress for flows in compound channels. Three calibrating coefficients need to be estimated for applying the SKM, namely eddy viscosity coefficient $(\lambda)$, friction factor $(f)$ and secondary flow coefficient $(k)$. There are several tested methods which can satisfactorily be used to estimate $\lambda, f$. However, the calibration of secondary flow coefficients $k$ to account for secondary flow effects correctly is still problematic. In this paper, the calibration of secondary flow coefficients is established by employing two approaches to estimate correct values of $k$ for simulating asymmetric compound channel with different side slopes of the internal wall. The first approach is based on Abril and Knight (2004) who suggest fixed values for main channel and floodplain regions. In the second approach, the equations developed by Devi and Khatua (2017) that relate the variation of the secondary flow coefficients with the relative depth $(\beta)$ and width ratio $(\alpha)$ are used. The results indicate that the calibration method developed by Devi and Khatua (2017) is a better choice for calibrating the secondary flow coefficients than using the first approach which assumes a fixed value of $k$ for different flow depths. The results also indicate that the boundary condition based on the shear force continuity can successfully be used for simulating rectangular compound channels, while the continuity of depth-averaged velocity and its gradient is accepted boundary condition in simulations of trapezoidal compound channels. However, the SKM performance for predicting the boundary shear stress over the shear layer region may not be improved by only imposing the suitable calibrated values of secondary flow coefficients. This is because difficulties of modelling the complex interaction that develops between the flows in the main channel and on the floodplain in this region.
\end{abstract}

Keywords Depth-averaged velocity $\cdot$ Boundary shear stress $\cdot$ Secondary flows $\cdot$ Shiono and Knight Method $\cdot$ Asymmetric compound channels

\section{Introduction}

Natural rivers are often connected to one or two floodplains on their sides. Consequently, the flow sections of rivers may be symmetric or asymmetric compound sections. In many

Ali H. Al-Aboodi

alialaboodi90@gmail.com

Wisam Alawadi

w.a.a.k.alawadi@edu.salford.ac.uk

Wisam S. Al-Rekabi

wesam752014@gmail.com

1 School of Computing Science and Engineering, Newton Building, University of Salford, Salford, UK

2 Department of Civil Engineering, College of Engineering, University of Basrah, Basrah, Iraq hydraulic projects, open channels are often designed and constructed as multi-stage compound channels to increase the stability of channel slopes and to carry different flow rates. Therefore, it is essential to understand the flow mechanism of compound channels with overbank flow conditions.

In straight compound channels, the longitudinal velocity in main river section is usually faster than that of floodplain. When these two faster and slower flows interact, exchange of mass and momentum occurs and yields a shear layer at the junction between the main channel and the floodplain. The main channel/floodplain interaction effects were first recognized and investigated by Sellin (1964) and Zheleznyakov (1972). Subsequently, many researchers demonstrated that the momentum transfer in a compound channel is the main reason for the non-uniformity of depth-averaged velocity and boundary shear stress (Myers and Elsawy 1975; Rajaratnam 
and Ahmadi 1979; Knight and Demetriou 1983; Knight and Hamed 1984). Due to the turbulence and secondary flow generating at the shear layer, the flow structure becomes more complex in an overbank flow case. Detailed experimental measurements have been conducted by Tominaga et al. (1989), Arnold et al. (1989), Shiono and Knight (1988, 1989), and Tominaga and Nezu (1991) to investigate experimentally the effects of turbulence quantities and secondary currents in the compound channels.

Flow velocity and boundary shear are the key hydraulic parameters when the overbank flow is hydraulically analysed. Therefore, a number of numerical and analytical models have been proposed to predict the lateral distributions of the depth-averaged velocity and the boundary shear stress in compound channels, for example (Krishnappan and Lau 1986; Shiono and Knight 1991; Huai et al. 2008; Yang et al. 2012). In general, most of the current analytical models used for calculating the depth-averaged flow are based on the Shiono and Knight Method (SKM) (Shiono and Knight 1991). The SKM is based on the RANS equations to provide quasi-2D model by which the lateral distributions of depthaveraged velocity and boundary shear stress across rivers and channels can simply be predicted. In SKM model, there are three hydraulic parameters: the bed friction $(f)$, lateral eddy viscosity $(\lambda)$, and the secondary flow term $(\Gamma)$ describe all possible energy losses mechanisms in 3D flows.

More recently, many investigations have been undertaken into flows in single and compound channels using SKM, focusing on the calibration parameters of the model. Abril and Knight (2004) provided a simple calibration approach to evaluate the three parameters required for applying SKM. They also showed that the secondary flow term may be assumed to be proportional to the gravitational term and suggested the secondary flow coefficient $(k)$ as a proportionality constant. Knight et al. (2007) analysed the modelling of the boundary shear in trapezoidal channels through investigating the effect of secondary flows on the boundary shear. Liao and Knight (2007) suggested a simple procedure for determining the analytic stage-discharge relationship, involving all three key parameters in SKM model, $f, \lambda$, and $\Gamma$. Rezaei and Knight (2009) employed the SKM to compute the depth-averaged velocity, the boundary shear stress, and the stage-discharge relationship in overbank flow of compound channels with non-prismatic floodplains. Based on a wide range of experimental data, Devi and Khatua (2017) proposed calibration expressions for secondary flow coefficients as a function of relative depth $(\beta)$ and with ratio $(\alpha)$. The relative depth is defined as the ratio of depth of flow on the floodplain to the flow depth in the main channel. Width ratio is defined as the ratio of the total width of the compound channel to the main channel bottom width. They demonstrated by applying SKM model to experimental channels and a natural river that the proposed expressions for secondary flow conditions help improve the performance of the SKM.

The present paper examines the capability of the SKM to predict the depth-averaged velocity and boundary shear stress for asymmetric rectangular and trapezoidal compound channels having a small width ratio $\alpha$. Such channels were rarely considered in the numerous works that made about applications of SKM. In this work, the focusing was on the calibration of the secondary flow parameter $(\Gamma)$. Therefore, two approaches are utilized for calibrating $\Gamma$. The first approach is based on fixed values suggested by Abril and Knight (2004), while the second approach is based on the calibration expressions proposed by Devi and Khatua (2017). Two different forms of boundary conditions at the internal wall between the main channel and the adjoining floodplain are also presented. The continuity of shear force is imposed for the rectangular main channel simulation, whereas the continuity of velocity and its gradient is applied for modelling the trapezoidal main channel.

\section{Theoretical basis of Shiono and Knight Method}

In SKM method, the streamwise depth-averaged momentum equation is solved for steady uniform turbulent flow. In a prismatic open channel, the equation for the streamwise component of momentum in a steady uniform flow may be combined with the continuity equation to give:

$\rho\left[\frac{\partial U V}{\partial y}+\frac{\partial U W}{\partial z}\right]=\rho g S_{\mathrm{o}}+\frac{\partial}{\partial y}(-\rho \overline{u v})+\frac{\partial}{\partial z}(\rho \overline{u w})$,

where $(U, V, W)$ are the mean velocity components in the $x$ (stream wise), $y$ (lateral) and $z$ (normal to bed) directions, respectively; $(u, v, w)$ are turbulent fluctuations of velocity with respect to the mean, $\rho$ is the density of water, $g$ is the gravitational acceleration and $S_{\mathrm{o}}$ is the bed slope. The depthaveraged momentum equation can be obtained by integrating Eq. (1) over the water depth, $H$, assumed $W(H)=W(0)=0$, as given by Shiono and Knight (1991):

$\rho g H S_{\mathrm{o}}+\frac{\partial H \bar{\tau}_{y x}}{\partial y}-\tau_{\mathrm{b}} \sqrt{1+\frac{1}{s^{2}}}=\frac{\partial\left[H(\rho U V)_{\mathrm{d}}\right]}{\partial y}$,

in which $\tau_{\mathrm{b}}$ is the bed shear stress, $s$ is the side slope (1:s = vertical: horizontal), and

$(\rho U V)_{\mathrm{d}}=\frac{1}{H} \int_{0}^{H}(\rho U V) \mathrm{d} z \quad$ and $\quad \bar{\tau}_{y x}=\frac{1}{H} \int_{0}^{H}(-\rho u v) \mathrm{d} z$.

Based on the commonly used eddy viscosity assumptions, the depth-averaged Reynolds stress $\left(\bar{\tau}_{y x}\right)$ can be given as follows: 
$\bar{\tau}_{y x}=\rho \bar{\varepsilon}_{y x} \frac{\partial U_{\mathrm{d}}}{\partial y} \quad$ and $\quad \bar{\varepsilon}_{y x}=\lambda U_{*} H$,

where $\bar{\varepsilon}_{y x}$ is depth-averaged eddy viscosity, $\lambda$ is the dimensionless eddy viscosity coefficient and $\left(U_{*}=\sqrt{\tau_{\mathrm{b}} / \rho}\right)$ is the local shear velocity. Using the customary flow resistance relationship that relates local boundary shear stress $\left(\tau_{\mathrm{b}}\right)$ with the depth-mean velocity $\left(U_{\mathrm{d}}\right)$ and the Darcy-Weisbach friction coefficient $(f), \tau_{\mathrm{b}}$ can be computed by:

$\tau_{\mathrm{b}}=\rho \frac{f}{8} U_{\mathrm{d}}^{2} \quad$ or $\quad U_{*}=\sqrt{\frac{f}{8}} U_{\mathrm{d}}$.

Then, substituting Eqs. (4) and (5) into (2) yields:

$\rho g H S_{\mathrm{o}}-\rho \frac{f}{8} U_{\mathrm{d}}^{2} \sqrt{1+\frac{1}{s^{2}}}+\frac{\partial}{\partial y}\left[\rho \lambda H^{2} \sqrt{\frac{f}{8}} U_{\mathrm{d}} \frac{\partial U_{\mathrm{d}}}{\partial y}\right]=\frac{\partial}{\partial y}\left[H(\rho U V)_{\mathrm{d}}\right]$.

Based on experimental results, the secondary flow term $(\rho U V)_{\mathrm{d}}$ is assumed to vary approximately linearly with respect to $y$. Therefore, the lateral gradient of the secondary flow force per unit length may be written as:

$\frac{\partial}{\partial y}\left[H(\rho U V)_{\mathrm{d}}\right]=\Gamma$,

where $\Gamma$ is a dimensionless secondary flow parameter which is different for each part of the flow.

Equation (6) can be solved to give $U_{\mathrm{d}}$ as a function of $y$ either analytically (Shiono and Knight 1991; Knight and Shiono 1996) or numerically (Knight and Abril 1996; Abril and Knight 2004). An analytical solution to Eq. (6) for the lateral distribution of depth-mean velocity, can be obtained as follows.

For a sub-area with a constant water depth $H$, the analytic $U_{\mathrm{d}}$ distribution is written in the form:

$U_{\mathrm{d}}=\left[A_{1} \mathrm{e}^{\gamma y}+A_{2} \mathrm{e}^{-\gamma y}+k\right]^{1 / 2}$,

where

$k=\frac{8 g S_{0} H}{f}(1-\beta)$,

$\gamma=\sqrt{\frac{2}{\lambda}}\left(\frac{f}{8}\right)^{\frac{1}{4}} \frac{1}{H}$

$\beta=\frac{\Gamma}{\rho g H S_{\mathrm{o}}}$.

For a sub-area with a main channel side slope of $1: s$, the $U_{\mathrm{d}}$ distribution has the form:

$U_{\mathrm{d}}=\left[A_{3} \xi^{\alpha}+A_{4} \xi^{-\alpha-1}+\omega \xi+\eta\right]^{1 / 2}$, where

$\alpha=-\frac{1}{2}+\frac{1}{2} \sqrt{1+\frac{s\left(1+s^{2}\right)^{\frac{1}{2}}}{\lambda}(8 f)^{\frac{1}{2}}}$,

$\omega=\frac{g S_{\mathrm{o}}}{\frac{\left(1+s^{2}\right)^{\frac{1}{2}}}{s}\left(\frac{f}{8}\right)-\frac{\lambda}{s^{2}}\left(\frac{f}{8}\right)^{\frac{1}{2}}}$,

$\eta=-\frac{\Gamma}{\frac{\left(1+s^{2}\right)^{\frac{1}{2}}}{s} \rho\left(\frac{f}{8}\right)}$,

$\xi=H-\frac{y-b}{s}$.

$A_{1}, A_{2}, A_{3}$ and $A_{4}$ are integration constants and can be determined by considering the relevant boundary conditions. The accurate prediction of depth averaged velocity and boundary shear stress depends on proper estimation of the three calibration parameters in SKM model (i.e. $f, \lambda$, and $\Gamma$ ) and specifying the appropriate boundary conditions.

\section{Description of data sets}

The SKM methodology is applied to data from experiments conducted by Sun (2007) on asymmetric compound channels that had different sizes and configurations as shown in Fig. 1. Three different data sets from Sun experiments were considered here so that different side slopes of the internal wall and wide range of flow depths can be covered. Table 1 summarises the data sets used, including information on geometrical and hydraulic conditions of the experiments.

The first set of experiments (SRC-1, SRC-2, and SRC$3)$ were undertaken in a small asymmetric rectangular compound channel for which; $B=0.306 \mathrm{~m}, L=12 \mathrm{~m}$, and $S_{\mathrm{o}}=0.001 \mathrm{~m} / \mathrm{m}$. The second set (including STC-1, STC-2, and STC-3) was performed using a trapezoidal compound channel whose width and slope are same as the first set. Large asymmetric compound channel having width of $0.915 \mathrm{~m}$ and slope of $0.002 \mathrm{~m} / \mathrm{m}$ was used by Sun (2007) for the third set of experiments (LC-1, LC-2). The flow section in this set was trapezoidal with internal wall inclined by slope of $(1 \mathrm{~V}: 1 \mathrm{H})$. In the first and second compound channel cases, the Manning coefficients $(n)$ were estimated as about 0.01 and the equivalent sand grain roughness height $\left(K_{\mathrm{s}}\right)$ as $0.3 \mathrm{~mm}$ for both the main channel and floodplain. For the large compound channel cases, the Manning coefficient for the main channel bed was estimated as 0.02 , whereas for the floodplain was 0.01 . The same values of Manning 


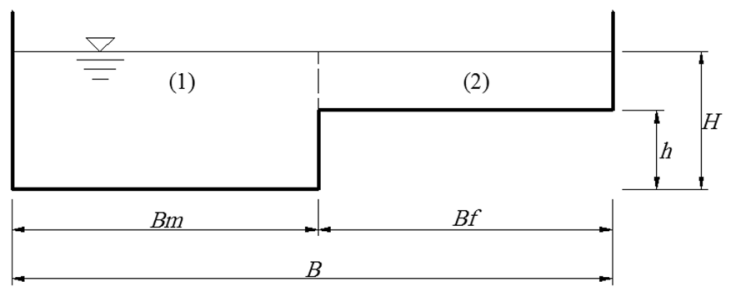

(a)

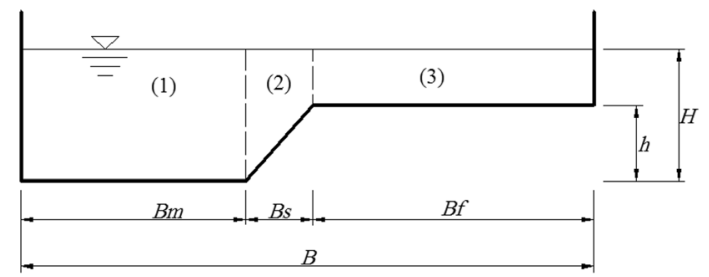

(b)

Fig. 1 Experimental channels used by Sun (2007): a rectangular compound channel, b trapezoidal compound channel

Table 1 Geometrical and hydraulic parameters for experimental compound channels considered

\begin{tabular}{|c|c|c|c|c|c|c|c|c|}
\hline Parameter & SRC-1 & SRC-2 & SRC-3 & STC-1 & STC-2 & STC-3 & LC-1 & LC-2 \\
\hline Flow depth $(H), \mathrm{cm}$ & 4.66 & 5.61 & 7.03 & 4.74 & 5.72 & 7.21 & 25.5 & 31.2 \\
\hline Relative depth $\left(D_{\mathrm{r}}\right)$ & 0.23 & 0.36 & 0.49 & 0.24 & 0.37 & 0.50 & 0.40 & 0.51 \\
\hline Width $(B), \mathrm{cm}$ & 30.6 & 30.6 & 30.6 & 30.6 & 30.6 & 30.6 & 91.5 & 91.5 \\
\hline Floodplain width $\left(B_{\mathrm{f}}\right), \mathrm{cm}$ & 15.0 & 15.0 & 15.0 & 15.0 & 15.0 & 15.0 & 36.5 & 36.5 \\
\hline Main channel width $\left(B_{\mathrm{m}}\right), \mathrm{cm}$ & 15.6 & 15.6 & 15.6 & 12.0 & 12.0 & 12.0 & 40.0 & 40.0 \\
\hline Sloped wall width $\left(B_{s}\right), \mathrm{cm}$ & 0.0 & 0.0 & 0.0 & 3.6 & 3.6 & 3.6 & 15.0 & 15.0 \\
\hline Slope $\left(S_{\mathrm{o}}\right), \mathrm{m} / \mathrm{m}$ & 0.001 & 0.001 & 0.001 & 0.001 & 0.001 & 0.001 & 0.002 & 0.002 \\
\hline Discharge $(Q), 1 / s$ & 2.15 & 3.62 & 5.73 & 1.91 & 3.36 & 5.58 & 129.96 & 172.52 \\
\hline Manning coefficient of main channel $\left(n_{\mathrm{mc}}\right)$ & 0.010 & 0.010 & 0.010 & 0.010 & 0.010 & 0.010 & 0.020 & 0.020 \\
\hline Manning coefficient of floodplain $\left(n_{\mathrm{fp}}\right)$ & 0.010 & 0.010 & 0.010 & 0.010 & 0.010 & 0.010 & 0.010 & 0.010 \\
\hline
\end{tabular}

coefficients estimated in the Sun experiments were used in simulations of test cases by the SKM model. In small-scale channel experiments (first and second sets), the velocity was measured using a pilot tube of $2.2 \mathrm{~mm}$ inner diameter, while an Acoustic Doppler Velocimeter (ADV) was used for measuring the velocity in the large-scale channel (third set). Preston tube was calibrated and used to measure the boundary shear stress for all channel cases. The diameters of the static and dynamic pressure pipes are 3.00 and $2.72 \mathrm{~mm}$, respectively. There are four circular holes with diameters of $0.54 \mathrm{~mm}$. A LPM5480, low-range, pressure transducer was connected to Preston tube to obtain the pressure difference $(\Delta p)$ between the dynamic and static pressures. The Patel calibration relationships were used to convert these pressure readings to boundary shear stresses. The Preston tube was calibrated so that it gives a measurement accuracy of $\pm 3 \%$.

\section{Application of SKM model}

\section{Boundary conditions}

The SKM modelling approach is applied through dividing the channel into a number of different panels and defining the boundary conditions to the domain. For a narrow asymmetric compound channel such as ones considered here, only two panels are often sufficient to simulate the flow by SKM (Yang et al. 2012). Thus, the rectangular compound channels considered in the present study were divided into two panels, one for the main channel and the other for the floodplain (Fig. 1). However, if trapezoidal compound channels are divided in a similar way to dividing rectangular compound sections, the panels will be of different depths on the sloping side region. Hence, the trapezoidal compound channels were simulated with three panels, one for each region, as shown in Fig. 1.

In addition to the selection of the number of panels, attention needs to be taken over the boundary conditions between panels and at the channel edges. For rectangular compound channels, the Dirichlet boundary condition, $U_{\mathrm{d}}=0$, was applied at $y=0$ (the remote edge of the main channel) and at $y=B$ (the remote edge of the floodplain). At the vertical internal wall between main channel and floodplain panels, there are difficulties in specifying boundary conditions as explored by Omran et al. (2008). However, Tang and Knight (2008) demonstrated based on their analysis of different boundary conditions that the following boundary condition with relationship for the continuity of shear force was technically the most suitable:

$\left(U_{\mathrm{d}}\right)_{y=b}^{(1)}=\left(U_{\mathrm{d}}\right)_{y=b}^{(2)}$, 
$\left(H \bar{\tau}_{y x}\right)_{y=b}^{(1)}+h \tau_{w}=\left(H \bar{\tau}_{y x}\right)_{y=b}^{(2)}$,

$\left(\varphi \frac{\partial U_{\mathrm{d}}^{2}}{\partial y}\right)_{y=b}^{(1)}=\left(\varphi \frac{\partial U_{\mathrm{d}}^{2}}{\partial y}\right)_{y=b}^{(2)}-h \tau_{w}$,

$\varphi=\frac{1}{2} \rho \lambda H^{2} \sqrt{f / 8} \quad$ and $\quad \tau_{w}=\rho\left(f U_{\mathrm{d}}^{2}\right)_{y=b} / 8$.

In the rectangular channel simulations, the boundary conditions given by Eqs. (17)-(20) were applied at vertical internal walls.

For trapezoidal compound channels, the internal wall is not vertical, so including the shear force on the internal wall in the boundary condition is not necessary. Thus, a boundary condition based on the continuity of $\left(H U_{\mathrm{d}}\right)$ and $U_{\mathrm{d}}$ gradient was applied when simulating the trapezoidal channels, and can be written as:

$\left(H U_{\mathrm{d}}\right)_{y=b}^{(1)}=\left(H U_{\mathrm{d}}\right)_{y=b}^{(2)}$ and $\left(\frac{\partial U_{\mathrm{d}}}{\partial y}\right)_{y=b}^{(1)}=\left(\varphi \frac{\partial U_{\mathrm{d}}}{\partial y}\right)_{y=b}^{(2)}$.

\section{Calibration for SKM model}

To obtain analytical solutions by SKM with an accepted accuracy, great care needs to be taken over the choice of the three calibration parameters $(f, \lambda$ and $\Gamma$ ) to be used in each panel. In the absence of detailed data about the distribution of the friction factor $(f)$ across the cross section of the channel, an overall friction factor could be used for each panel (Omran and Knight 2010). $f$ was therefore computed from the corresponding Manning's coefficient ( $n$ ) and applied as a constant in main channel and floodplain panels. The equivalent roughness height $k_{\mathrm{s}}$ was first calculated from $n$ by the relationship expressed as (Ackers 1991):

$k_{\mathrm{s}}=(8.25 \sqrt{g} n)^{6}$.

The modified Colebrook-White equation was then used to calculate the local friction factor for each panel with knowing the water depth $H$ (Rameshwaran and Shiono 2007):

$f=\left[-2 \log \left(\frac{3.02 v}{\sqrt{128 g H^{3} S_{\mathrm{o}}}}+\frac{k_{\mathrm{s}}}{12.3 H}\right)\right]^{-2}$,

where $\nu$ is kinematic viscosity and $H$ is the flow depth in the main channel or the floodplain panel. Adopting this concept to test cases SRC, STC, and LC, the zonal friction factors were calculated and listed in Table 2.
Table 2 Friction factors for all test cases

\begin{tabular}{lll}
\hline Case & \multicolumn{2}{l}{ Friction factor $(f)$} \\
\cline { 2 - 3 } & Main channel & Floodplain \\
\hline SRC-1 & 0.0260 & 0.0464 \\
SRC-2 & 0.0245 & 0.0352 \\
SRC-3 & 0.0228 & 0.0288 \\
STC-1 & 0.0259 & 0.0449 \\
STC-2 & 0.0243 & 0.0345 \\
STC-3 & 0.0227 & 0.0283 \\
LC-1 & 0.0509 & 0.0201 \\
LC-2 & 0.0471 & 0.0179 \\
\hline
\end{tabular}

A priori chosen values for the dimensionless eddy viscosity $\lambda$ are also needed to be estimated for each panel. Abril and Knight (2004) and Knight et al. (2007) demonstrated that the $\lambda$ value has no significant influence on the SKM prediction. Therefore, in this study, a constant value $\lambda_{\mathrm{mc}}=0.07$ proposed by Knight et al. (2004) was used in the main channel panel. For floodplain panel a variable value of $\lambda_{\mathrm{fp}}$ was estimated depending on $D_{\mathrm{r}}$ (local relative depth given by $\left.H(y) / H_{\max }\right)$ and using the calibration equation proposed by Abril and knight (2004):

$\lambda_{\mathrm{fp}}=\lambda_{\mathrm{mc}}\left(-0.2+1.2 D_{\mathrm{r}}^{-1.44}\right)$.

Calibrating the third parameter of the secondary flows term $(\Gamma)$ is usually more difficult than determining the other two parameters (i.e. $f$ and $\lambda$ ). Nevertheless, Shiono and Knight (1990) indicated that within certain zones, the gradient of the secondary flow term was constant, allowing a constant value of $\Gamma$ to be assigned to each individual panel. Two approaches were used to determine $\Gamma$ for each panel. They are the approach developed by Abril and Knight (2004) and the approach proposed by Devi and Khatua (2017). The first approach is based on the theoretical concept that links boundary shear stress and secondary flow to give finally two simple equations:

$\Gamma=k_{\mathrm{mc}}\left(\rho g H_{\mathrm{mc}} S_{\mathrm{o}}\right)$,

$\Gamma=k_{\mathrm{fp}}\left(\rho g H_{\mathrm{fp}} S_{\mathrm{o}}\right)$,

where $k$ is defined as the secondary flow coefficient, and the subscripts mc and fp refer to the main channel and flood plain, respectively. The coefficients $\left(k_{\mathrm{mc}}=0.15\right.$ and $\left.k_{\mathrm{fp}}=-0.25\right)$ were suggested by Abril and Knight (2004) as calibrated values based on the Flood Channel Facility data for different relative depths in a straight compound channel.

The second approach was developed by Devi and Khatua (2017) based on a wide range of experimental data obtained from asymmetric compound channels with different relative flow depths $(\beta)$ and width ratios $(\alpha)$. 
This approach primarily uses the average boundary shear stress per panel $\left(\tau_{\text {avg. }}\right)$ and driving force per unit wetted area $\left(\rho g H S_{\mathrm{o}}\right)$ to calculate the secondary flow where $\Gamma$ for each panel is given by the following:

$\Gamma_{\mathrm{mc}}=\rho g H S_{\mathrm{o}}-\tau_{\mathrm{avgmc}} \quad$ or $\quad \Gamma_{\mathrm{mc}}=\rho g H S_{\mathrm{o}}\left(1-k_{\mathrm{mc}}^{\prime}\right)$,

$\Gamma_{\mathrm{fp}}=\rho g H S_{\mathrm{o}}-\tau_{\mathrm{avgfp}} \quad$ or $\quad \Gamma_{\mathrm{fp}}=\rho g H S_{\mathrm{o}}\left(1-k_{\mathrm{fp}}^{\prime}\right)$,

where $k_{\mathrm{mc}}^{\prime}$ and $k_{\mathrm{fp}}^{\prime}$ are given by:

$k_{\mathrm{mc}}^{\prime}=\frac{\tau_{\text {avgmc }}}{\rho g H S_{\mathrm{o}}}, \quad k_{\mathrm{fp}}^{\prime}=\frac{\tau_{\text {avgfp }}}{\rho g H S_{\mathrm{o}}}$.

Comparing Eqs. (25) and (26) with Eqs. (27) and (28), it can be concluded that $k=1-k^{\prime}$.

The $k_{\mathrm{s}}^{\prime}$ value for the side slope region in a trapezoidal compound channel is expressed as:

$k_{\mathrm{s}}^{\prime}=\frac{\tau_{\text {avgs }}}{\rho g H^{\prime} S_{\mathrm{o}}}$,

where $H^{\prime}$ is the average flow depth of side slope region. Based on the multilinear regression analysis, Devi and Khatua (2017) formulated the dependency of their secondary flow coefficients $\left(k_{\mathrm{mc}}^{\prime}, k_{\mathrm{fp}}^{\prime}\right.$ and $\left.k_{\mathrm{s}}^{\prime}\right)$ with the non-dimensional parameters, i.e., relative flow depth $(\beta)$ and width ratio $(\alpha)$, by the following equations:

$k_{\mathrm{mc}}^{\prime}=-0.5+0.45 \mathrm{e}^{-0.66 \beta}+1.1 \alpha^{-0.38}$,

$k_{\mathrm{fp}}^{\prime}=0.18+0.79 \beta^{-0.28}-0.013 \alpha$,

$k_{\mathrm{s}}^{\prime}=0.01-0.474 \beta+2.06 \alpha^{-0.4}$.

Table 3 presents the secondary flow coefficients for main channel, side slope and floodplain panels calculated using Eqs. (31)-(33).

\section{Results and discussion}

\section{Depth-averaged velocity distribution}

Figure 2 shows a comparison between the predicted and measured lateral distributions of the depth-averaged mean streamwise velocity for the small scale cases (SRC and STC). In the figure, the secondary flow coefficients are first assumed to be constant $\left(k_{\mathrm{mc}}=0.15, k_{\mathrm{fp}}=-0.25\right)$ according to Abril and Knight approach, as shown by the dashed line. It can be seen in Fig. 2a, d for lower flow cases (SRC-1 and STC-1) that the prediction for the main channel is overpredicted, but for the floodplain is underestimated. Figure 2a, $\mathrm{d}$ also indicates that the results can be improved when the secondary flow coefficients used in SKM are calibrated values based on Devi and Khatua approach, as shown in the sold line. This improvement in results of SKM may be explained by reference to secondary flow coefficients defined in Eqs. (31) and (32). Devi and Khatua approach empirically considered the momentum exchange at the junction between main channel and flood plain at low flow depths, increasing subsequently a value of $k$ to more than 0.15 , and improving the prediction of the velocity particularly in the main channel region. However, the velocity is slightly overpredicted in the flood plain. This is thought to be as a result of relatively high values of secondary flow coefficients (about $k_{\mathrm{fp}}=-0.35$ ) being calculated by Eq. (32) for this region.

For higher flow cases (SRC-3 and STC-3) with high relative depths, velocity results are overpredicted in both main channel and floodplain regions, when secondary flow coefficients are fixed at their standard values $\left(k_{\mathrm{mc}}=0.15\right.$, $\left.k_{\mathrm{fp}}=-0.25\right)$ based on Abril and Knight calibration approach (Fig. 2c, f). Meanwhile the same figures indicate that simulated depth-averaged velocity by SKM improves significantly, when secondary flow coefficients are adjusted by the approach proposed by Devi and Khatua (2017). This arises because of the high value of secondary flow coefficient calculated by Devi and Khatua equations for a main channel region, where the effect of secondary flow is expected to be strong in the case of high flow. For cases SRC-2 and
Table 3 Secondary flow coefficients for all test cases based on Devi and Khatua equations

\begin{tabular}{lllllllll}
\hline Case [\#] & $\beta$ & $\alpha$ & $k_{\mathrm{mc}}^{\prime}$ & $k_{\mathrm{fp}}^{\prime}$ & $k_{\mathrm{s}}^{\prime}$ & $k_{\mathrm{mc}}\left(1-k_{\mathrm{mc}}^{\prime}\right)$ & $k_{\mathrm{fp}}\left(1-k_{\mathrm{fp}}^{\prime}\right)$ & $k_{\mathrm{s}}\left(1-k_{\mathrm{s}}^{\prime}\right)$ \\
\hline SRC-1 & 0.23 & 1.96 & 0.74 & 1.35 & - & 0.26 & -0.35 & - \\
SRC-2 & 0.36 & 1.96 & 0.71 & 1.21 & - & 0.29 & -0.21 & - \\
SRC-3 & 0.49 & 1.96 & 0.68 & 1.12 & - & 0.32 & -0.12 & - \\
STC-1 & 0.24 & 2.55 & 0.65 & 1.32 & 1.31 & 0.35 & -0.32 & -0.31 \\
STC-2 & 0.37 & 2.55 & 0.62 & 1.19 & 1.25 & 0.38 & -0.19 & -0.25 \\
STC-3 & 0.50 & 2.55 & 0.59 & 1.11 & 1.19 & 0.41 & -0.11 & -0.19 \\
LC-1 & 0.40 & 2.29 & 0.65 & 1.17 & 1.30 & 0.35 & -0.17 & -0.30 \\
LC-2 & 0.51 & 2.29 & 0.62 & 1.10 & 1.25 & 0.38 & -0.10 & -0.25 \\
\hline
\end{tabular}


(a) SRC-1

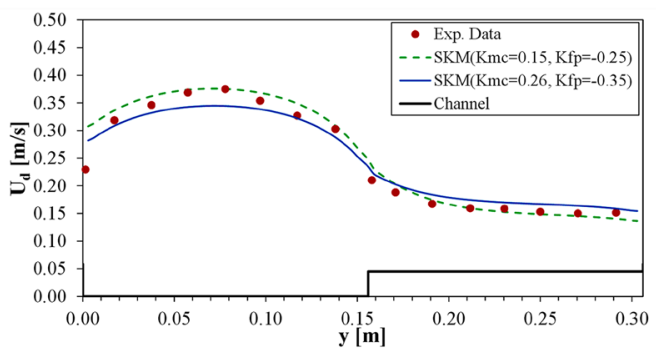

(b) SRC-2

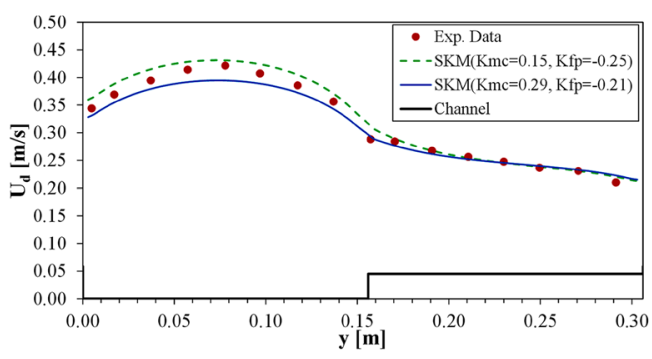

(c) SRC-3

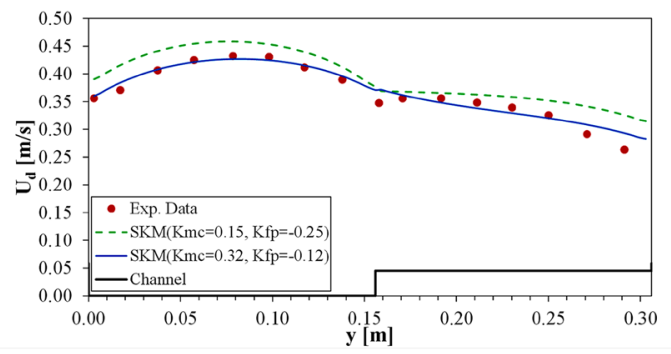

(d) STC-1

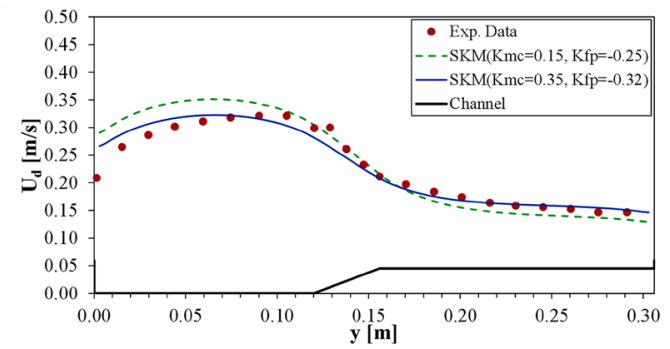

(e) STC-2

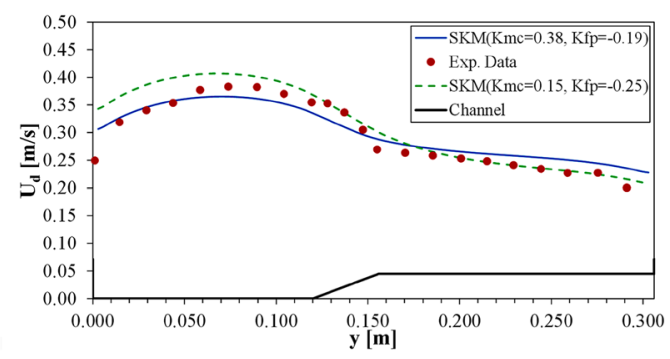

(f) STC-3

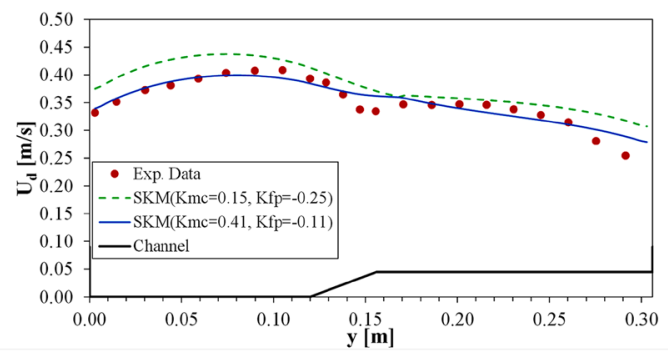

Fig. 2 Results of velocity simulations for small-scale compound channels (the solid line: $k$ calibrated by Devi and Khatua approach, the dashed line: $k$ assumed as Abril and Knight approach)

STC-2, Fig. 2b, e indicates that SKM model with calibrated values of $k$ proposed by Abril and Knight is able to predict the depth-averaged velocity well in the floodplain region, but it is not in the main channel region. On the other hand, including $k$ coefficients calibrated by using Devi and Khatua equations can give a closer result to experimental data in both regions.

In applying the model to the large-scale channel, the secondary flow coefficients are also calibrated based on the two approaches that were described previously. Figure 3 (a) LC-1

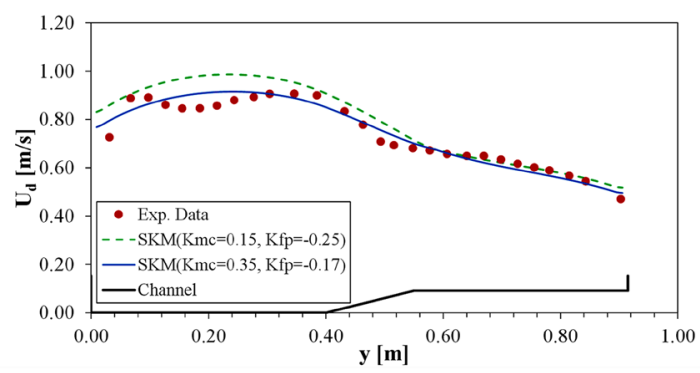

(b) LC-2

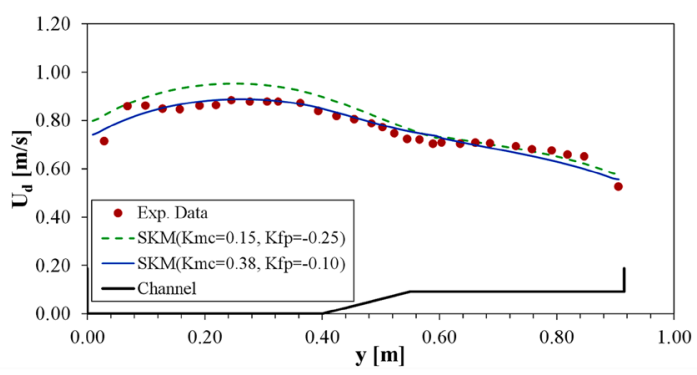

Fig. 3 Results of velocity simulations for large-scale compound channels (the solid line: $k$ calibrated by Devi and Khatua approach, the dashed line: $k$ assumed as Abril and Knight approach) 
shows the application of the SKM model to the large scale channel, cases LC-1 and LC-2, with dividing the channel into three panels. It can be seen that the predictions of $U_{\mathrm{d}}$ for both cases closely agree with the experimental values particularly in the main channel, when secondary flow coefficients included in SKM are calibrated by Devi and Khatua approach. In contrast, if the secondary flow effect is described by the constant values suggested by Abril and Knight (2004), the velocity is overpredicted for main channel. This is related to the representation of the strong secondary flow in high flows, which can be defined well through the calibration approach developed by Devi and Khatua (2017).

\section{Boundary shear stress distribution}

For investigating the influence of secondary flow effects on the lateral distribution of boundary shear stress $\left(\tau_{\mathrm{b}}\right)$ in asymmetric compound channels with different internal walls (vertical and inclined), the SKM results were compared to those obtained from Sun (2007) experiments. Figure 4 shows the predicted results and experimental data of $\tau_{\mathrm{b}}$ for the rectangular channel cases (SRC) and trapezoidal channel cases (STC). It can be seen that the predictions of $\tau_{\mathrm{b}}$, with including secondary flow coefficients calibrated by Devi and Khatua approach, closely agree with the experimental values in both cases of channel configurations. However, for STC cases (trapezoidal section), the prediction of $\tau_{\mathrm{b}}$ somewhat disagrees with the experimental values in the junction region between the main channel and the floodplain, particularly in low flow cases. This is likely to be due to the applied boundary condition which may not be suitable with such cases, where a strong interaction develop between the flows in the main channel and on the floodplain. From Fig. 4, it is also clear that use of secondary flow coefficients $\left(k_{\mathrm{mc}}=0.15\right.$, $\left.k_{\mathrm{fp}}=-0.25\right)$ gives prediction values of $\tau_{\mathrm{b}}$ that largely disagree with the experimental values, in particular in main channel. This means, using the generic values of $k$ adopted by Abril and Knight (2004) is not sufficient for obtaining a (a) SRC-1

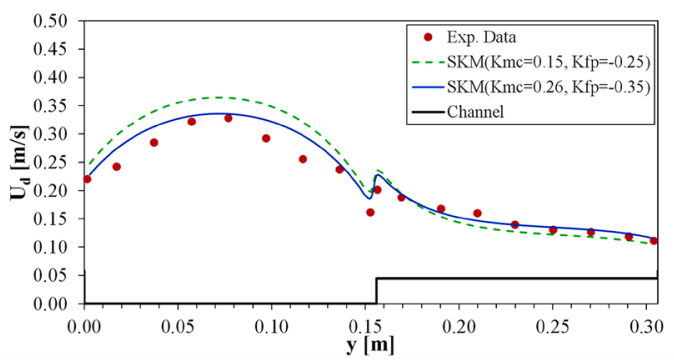

(b) SRC-2

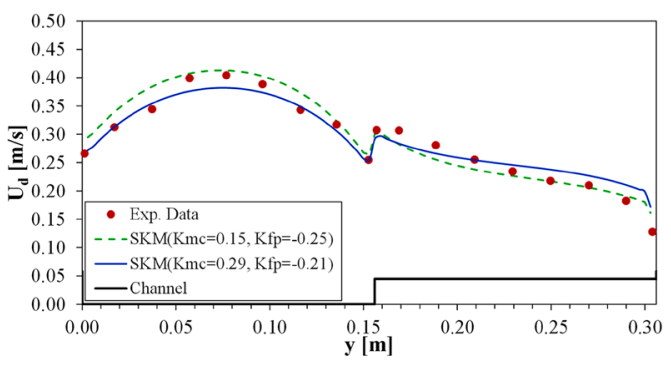

(c) SRC-3

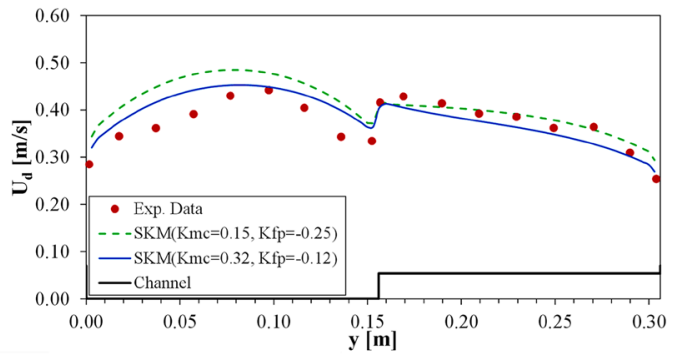

(d) STC-1

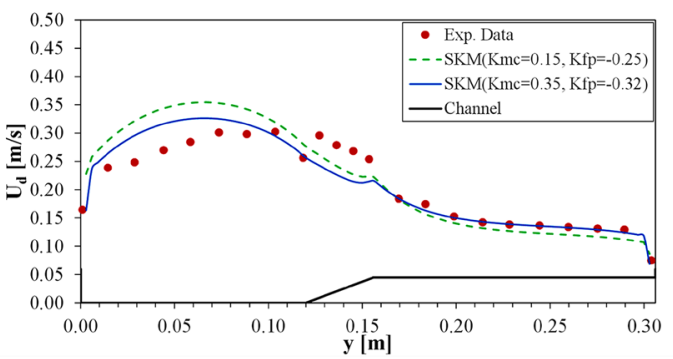

(e) STC-2

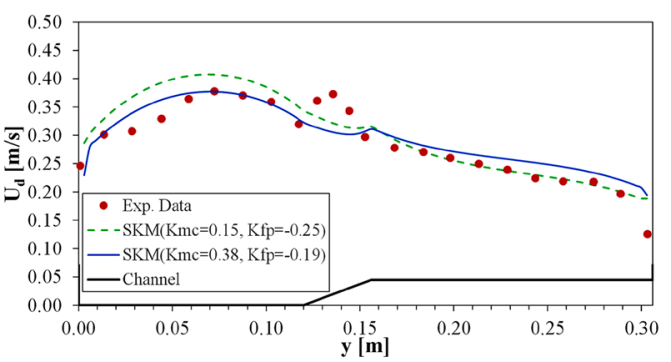

(f) STC-3

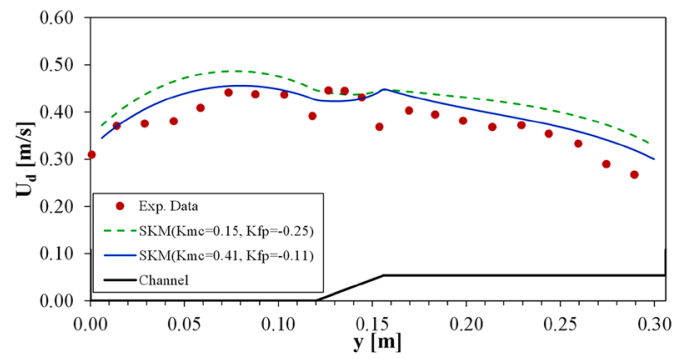

Fig. 4 Results of boundary shear stresses for small-scale compound channels (the solid line: $k$ calibrated by Devi and Khatua approach, the dashed line: $k$ assumed as Abril and Knight approach) 
(a) LC-1

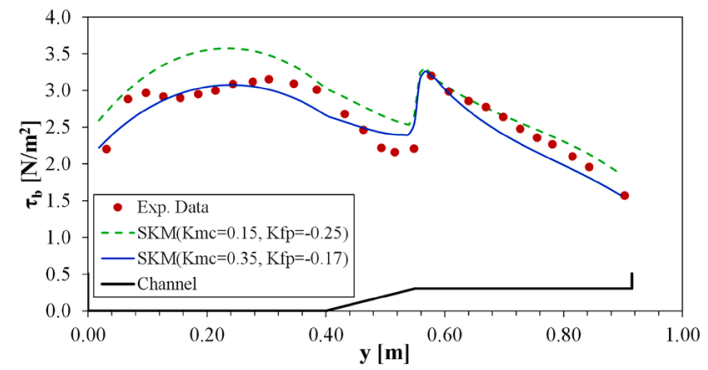

(b) LC-2

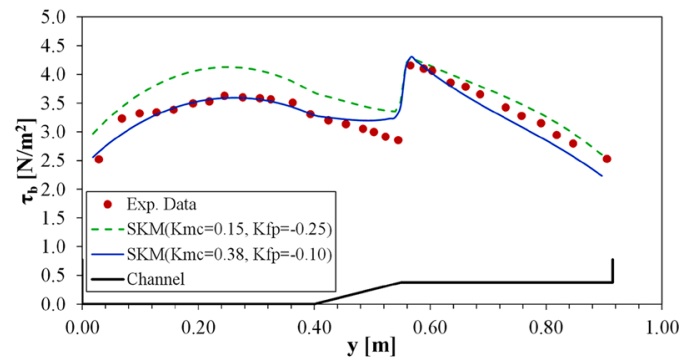

Fig. 5 Results of boundary shear stresses for large-scale compound channels (the solid line: $k$ calibrated by Devi and Khatua approach, the dashed line: $k$ assumed as Abril and Knight approach)

good prediction of boundary shear stress distributions. Additionally, Fig. 4 indicates that despite the discontinuity of the flow depth in rectangular compound channels, SKM can give good predictions for $\tau_{\mathrm{b}}$ when the boundary condition based on the continuity of the shear force is implemented.

Simulations using SKM have also been carried out on large scale cases (LC-1 and LC-2) in experiments of Sun (2007) as shown in Fig. 5. The comparison with experimental data indicates that including the calibrated coefficients obtained from Devi and Khatua approach is indeed a reasonable choice for improving the predictions of boundary shear stresses. Based on the Devi and Khatua approach, the secondary flow coefficient values are found to be greater for smaller width ratio. Since the compound channels considered here have a small width ratio, the $k$ values calibrated by Devi and Khatua approach were higher than those assumed in Abril and Knight approach. This in turn improves the prediction of the boundary shear stress. However, likewise the small-scale cases, there are still difficulties in the calculation of boundary shear stress over the shear layer region. To improve the results in this region, it requires that the channel be further divided. Nevertheless, applying SKM model with just three panels to obtain predicted results with a small error can be justified for practical purposes.

\section{Conclusions}

In this research, the SKM model was verified against the small-scale and large-scale asymmetric compound channel data from experiments of Sun (2007) at Loughborough University. The present work focused on the calibration of the secondary flow coefficients that play an important role in simulating the compound channel flows by SKM. Two approaches have been used for calibrating secondary flow coefficients $(k)$. In the first approach, the values of $k$ are kept constant as per the method proposed by April and Knight (2004). In the second approach, which developed by Devi and Khatua (2017), the secondary flow coefficients are varying depending on the relative depths $(\beta)$ and width ratios $(\alpha)$.

The comparison between predicted and experimental data indicated that SKM predictions for the depth-averaged velocity and boundary shear stress improve significantly when calibrated secondary coefficients based on Devi and Khatua (2017) are used. The results also indicated that rectangular compound channel with vertical internal wall can correctly be simulated by SKM when the continuity of shear force boundary condition together with secondary flow coefficients calibrated by Devi and Khatua approach are applied. However, the velocity and the shear stress for the floodplain are not predicted as accurate as in the main channel. This may be due to slightly low values of $k$ produced from Eqs. (31)-(33). For trapezoidal compound channels which have inclined internal walls, SKM provides better results for all experimental channels considered in this study, when the secondary flow coefficients are adjusted by Devi and Khatua approach. Nevertheless, the boundary shear stress distributions obtained using the SKM were not at the same magnitude of the accuracy as that of velocity distributions, particularly in the shear layer region. This is likely to be related to the strong interaction that may develop between the flows in the main channel and on the floodplain in this region.

Open Access This article is distributed under the terms of the Creative Commons Attribution 4.0 International License (http://creativecomm ons.org/licenses/by/4.0/), which permits unrestricted use, distribution, and reproduction in any medium, provided you give appropriate credit to the original author(s) and the source, provide a link to the Creative Commons license, and indicate if changes were made.

\section{References}

Abril J, Knight D (2004) Stage-discharge prediction for rivers in flood applying a depth-averaged model. J Hydraul Res 42(6):616-629

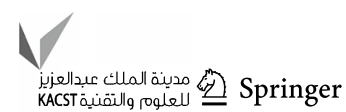


Ackers P (1991) Hydraulic design of straight compound channels. Hydraulics Research Ltd, Wallingford

Arnold U, Stein J, Rouv G (1989) Sophisticated measurement technique for experimental investigation of compound open channel flow. In: Maksimovic C, Radojkovic M (eds) Computational modelling and experimental methods in hydraulics. Elsevier, London, pp 11-21

Devi K, Khatua K (2017) Depth-averaged velocity and boundary shear stress prediction in asymmetric compound channels. Arab J Sci Eng 42(9):3849-3862

Huai W, Xu Z, Yang Z, Zeng Y (2008) Two dimensional analytical solution for a partially vegetated compound channel flow. Appl Math Mech 29(8):1077-1084

Knight D, Abril CJ (1996) Refined calibration of a depth-averaged model for turbulent flow in a compound channel. Proc Inst Civ Eng Water Marit Energy 118(3):151-159

Knight D, Demetriou J (1983) Flood plain and main channel flow interaction. J Hydraul Eng 109(8):1073-1092

Knight D, Hamed M (1984) Boundary shear in symmetrical compound channels. J Hydraul Eng 110(10):1412-1430

Knight DW, Shiono K (1996) River channel and floodplain hydraulics. In: Anderson MG, Walling DE, Bates PD (eds) Floodplain Processes, Chap 5, Wiley, New York, pp 139-181

Knight DW, Omran M, Abril JB (2004) Boundary conditions between panels in depth averaged flow models revisited. In: River Flow 2004: Proceedings of the 2 nd international conference on fluvial hydraulics, 23-25 June, vol 1. Napoli, Italy, pp 371-380

Knight D, Omran M, Tang X (2007) Modeling depth-averaged velocity and boundary shear in trapezoidal channels with secondary flows. J Hydraul Eng 133(1):39-47

Krishnappan B, Lau Y (1986) Turbulence modeling of flood plain flows. J Hydraul Eng 112(4):251-266

Liao H, Knight D (2007) Analytic stage-discharge formulas for flow in straight prismatic channels. J Hydraul Eng 133(10):1111-1122

Myers R, Elsawy E (1975) Boundary shear in channel with flood plain. J Hydraul Div 101(7):933-946

Omran M, Knight D (2010) Modelling secondary cells and sediment transport in rectangular channels. J Hydraul Res 48(2):205-212

Omran M, Atabay S, Knight DW, Seckin G (2008) Boundary conditions for a depth-averaged flow model in overbank flow. In: Altinakar MS, Kokpinar MA, Aydin I, Cokgar S, Kirkgoz S (eds) River Flow 2008, vol 1. Cesme, Turkey, pp 485-492

Rajaratnam N, Ahmadi R (1979) Interaction between main channel and flood-plain flows. J Hydraul Div 105(5):573-588

Rameshwaran P, Shiono K (2007) Quasi two-dimensional model for straight overbank flows through emergent. J Hydraul Res $45(3): 302-315$
Rezaei B, Knight D (2009) Application of the Shiono and Knight Method in compound channels with non-prismatic floodplains. J Hydraul Res 47(6):716-726

Sellin RHJ (1964) A laboratory investigation into the interaction between the flow in the channel of a river and that over its flood plain. La Houille Blanche 20(7):793-802

Shiono K, Knight D (1988) Two-dimensional analytical solution for a compound channel. In: Proceedings of 3rd International Symposium on refined flow modeling and turbulence measurements, pp 503-510

Shiono K, Knight D (1989) Transverse and vertical Reynolds stress measurements in a shear layer region of a compound channel. In: Proceedings of 7th Symposium Turb. Shear Flows, Stanford pp 1-6

Shiono K, Knight DW (1990) Mathematical models of flow in two or multi stage straight channels. In: Proceedings of international conference on river flood hydraulics, Wiley, New York, pp 229-238

Shiono K, Knight D (1991) Turbulent open-channel flows with variable depth across the channel. J Fluid Mech 222:617-646

Sun X (2007). Flow characteristics in compound channels with and without vegetation. Loughborough University: Doctoral dissertation, (C) Xin Sun

Tang X, Knight DW (2008) Lateral depth-averaged velocity distributions and bed shear in rectangular compound channels. J Hydraul Eng 134(9): 1337-1342

Tominaga A, Nezu I (1991) Turbulent structure in compound openchannel flows. J Hydraul Eng 117(1):21-41

Tominaga A, Nezu I, Ezaki K, Nakagawa H (1989) Three-dimensional turbulent structure in straight open channel flows. J Hydraul Res 27(1):149-173

Yang K, Nie R, Liu X, Cao S (2012) Modeling depth-averaged velocity and boundary shear stress in rectangular compound channels with secondary flows. J Hydraul Eng 139(1):76-83

Zheleznyakov GV (1972) Interaction of Channel and Floodplain Streams. In: Proceedings of the 14th International Association for Hydraulic Research (IAHR) Conference. Paris, France, IAHR, Delft, The Netherlands, pp 145-148

Publisher's Note Springer Nature remains neutral with regard to jurisdictional claims in published maps and institutional affiliations. 